\title{
THE
}

\section{Infantile exposure to lead and late-age cognitive decline: Relevance to $A D$}

\author{
Syed Waseem Bihaqi \\ University of Rhode Island \\ Azadeh Bahmani \\ University of Rhode Island \\ Gehad M. Subaiea \\ University of Rhode Island
}

Nasser H. Zawia

University of Rhode Island, nzawia@uri.edu

Follow this and additional works at: https://digitalcommons.uri.edu/bps_facpubs

This is a pre-publication author manuscript of the final, published article.

Creative Commons License

\section{c) $($ ) $९$}

This work is licensed under a Creative Commons Attribution-Noncommercial-No Derivative Works 4.0 License.

\section{Citation/Publisher Attribution}

Bihaqi, S. W., Bahmani, A., Subaiea, G. M., \& Zawia, N. H. (2014). Infantile exposure to lead and late-age cognitive decline: Relevance to AD. Alzheimer's \& Dementia, 10(2), 187-195. doi: 10.1016/ j.jalz.2013.02.012 Available at: https://doi.org/10.1016/j.jalz.2013.02.012

This Article is brought to you for free and open access by the Biomedical and Pharmaceutical Sciences at DigitalCommons@URI. It has been accepted for inclusion in Biomedical and Pharmaceutical Sciences Faculty Publications by an authorized administrator of DigitalCommons@URI. For more information, please contact digitalcommons-group@uri.edu. 


\title{
Infantile exposure to lead and late-age cognitive decline: Relevance to AD
}

\author{
Syed Waseem Bihaqia ${ }^{\text {, Azadeh Bahmani }}{ }^{b}$, Gehad M. Subaiea ${ }^{a}$, and Nasser H. Zawiaa,b, \\ aDepartment of Biomedical and Pharmaceutical Sciences, University of Rhode Island, Kingston, \\ RI, USA \\ 'Interdisciplinary Neuroscience Program (INP), University of Rhode Island, Kingston, RI, USA
}

\section{Abstract}

\begin{abstract}
Background-Early-life lead $(\mathrm{Pb})$ exposure induces overexpression of the amyloid beta precursor protein and its amyloid beta product in older rats and primates. We exposed rodents to $\mathrm{Pb}$ during different life span periods and examined cognitive function in old age and its impact on biomarkers associated with Alzheimer's disease (AD).
\end{abstract}

Methods-Morris, Y, and the elevated plus mazes were used. Western blot, quantitative polymerase chain reaction (qPCR), and enzyme-linked immunosorbent assay were used to study the levels of $\mathrm{AD}$ biomarkers.

Results-Cognitive impairment was observed in mice exposed as infants but not as adults. Overexpression of AD-related genes (amyloid beta precursor protein and $\beta$-site amyloid precursor protein cleaving enzyme 1) and their products, as well as their transcriptional regulatorspecificity protein 1 (Sp1) - occurred only in older mice with developmental exposure to $\mathrm{Pb}$.

Conclusions- $\mathrm{A}$ window of vulnerability to $\mathrm{Pb}$ neurotoxicity exists in the developing brain that can influence AD pathogenesis and cognitive decline in old age.

\section{Keywords}

Aging; Alzheimer's disease; Cognition; Development; Lead; Life span

\section{Introduction}

Alzheimer's disease (AD) is the most common form of dementia affecting elderly people. The main characteristic features of $\mathrm{AD}$ include accumulation of senile plaques composed of aggregated amyloid beta $(\mathrm{A} \beta)$, neurofibrillary tangles enriched with phosphorylated tau, and synaptic loss in the brain resulting in cognitive decline [1,2]. Although the familial form of $\mathrm{AD}$ is determined genetically, late-onset $\mathrm{AD}$ (LOAD) is sporadic and represents $\sim 95 \%$ of $\mathrm{AD}$ cases. In addition, it is unknown whether the onset of events that result in LOAD are part of aging or have earlier developmental beginnings.

Previous reports by us on both rodents and primates have shown that early life exposure to the environmental metal lead $(\mathrm{Pb})$ resulted in a latent overexpression of genes and proteins associated with the amyloid pathway, and enhancement of AD pathology in primates [3,4]. Recently, we have also found that both total tau and its phosphorylated forms, as well tau

(C) 2013 The Alzheimer's Association. All rights reserved.

*Corresponding author. Tel.: +401-874-5909; Fax: +401-874-2516. nzawia@uri.edu. 
deposits, were elevated in both aging rodents and primates previously exposed to $\mathrm{Pb}$ as infants (data under publication review). These findings provide evidence that molecular events occurring during critical periods of brain development are reprogrammed by environmental exposure to promote AD-like pathogenesis late in life. Also, we have reported genomewide messenger RNA (mRNA) expression profiling and methylomic analysis that reveal the scope of reprogramming of gene expression in the aging brain as a result of early life exposure and its connection to epigenetic mechanisms acting at the developmental stage [5,6].

Epidemiologic data that demonstrate a link between early life exposure to an environmental agent and LOAD are limited. The Normative Aging Study investigated the link between past nonoccupational $\mathrm{Pb}$ exposure and cognitive decline. Investigators reported that higher levels of $\mathrm{Pb}$ in blood and/or bone were accompanied by poor cognitive performance in different cognitive tests, including the Wechsler Adult Intelligence Scale-Revised, the Consortium to Establish a Registry for Alzheimer's Disease and the Mini-Mental State Examination [710]. In a subgroup of the Nurses' Health Study, Weuve and colleagues [11] reported that higher levels of $\mathrm{Pb}$ in the tibia was associated with poor test scores on the Mini-Mental State Examination.

Multiple animal studies by us have demonstrated a link between early life exposure to this environmental agent and amyloidogenesis in old age [3,4,12]; however, although these studies are compelling, behavioral analysis was lacking to demonstrate the functional impact of early exposure on cognition in old age. Here we present the findings from a 2-year life span study in rodents that tested the impact of $\mathrm{Pb}$ exposure on cognitive function in the aging rodent brain, and examined its relationship to critical periods of exposure (both developmental and adult) and their impact on biochemical and molecular pathways associated with $\mathrm{AD}$ pathogenesis in the same cohort of animals.

\section{Methods}

\subsection{Animal exposure}

C57BL/6 mice were bred in-house at the University of Rhode Island. Postnatal day 1 (PND 1) was designated as 24 hours after birth. All pups were pooled, and new litters consisting of 10 males were selected randomly and placed with each dam. The animals were divided into four groups. The control group received regular tap water. The second group $(\mathrm{PbE}$, the early $\mathrm{Pb}$ exposure group) was exposed to $0.2 \% \mathrm{~Pb}$ acetate from PND 1 to PND 20 through drinking water of the dam. The third group ( $\mathrm{PbA}$, the adult lead exposure group) was exposed to $\mathrm{Pb}$ daily for 3 months starting at 7 months of age. The fourth group $(\mathrm{PbEA}$, the early and adult $\mathrm{Pb}$ exposure group [reexposure as adults]) was exposed to $\mathrm{Pb}$ developmentally (PND 1 to PND 20) and during adulthood (7-9 months of age). Brains were dissected at different ages—eight mice at PNDs 20, 180, 270, 540, and 700—and brain frontal cortex tissues were stored at $-80^{\circ} \mathrm{C}$ until use.

\subsection{Behavioral tests}

Behavioral testing was conducted on selected time points (PND 540 and PND 700). To assess spatial learning and memory (a hippocampal formation-dependent task), animals were tested in the Morris water maze task and for the transfer latency (TL) in the elevated plus maze. Measuring the spontaneous alternations in the $\mathrm{Y}$ maze also assessed working memory function.

2.2.1. Morris water maze-The test was performed following the method of Morris and colleagues [13]. Each animal received three trials per day for 7 days with a 20-minute 
intertrial interval. A retention test (probe trail) was performed on the eighth day, and the percentage of time and distance traveled in the target quadrant for 60 seconds was recorded. Swim distance and latencies to locate the platform were videotaped and analyzed with a computerized video tracking system (ObjectScan, Clever Systems Inc.). Training and retention tests were conducted between 0900 нг and $1600 \mathrm{HR}$.

2.2.2. Y maze training procedure-Spontaneous alternation was tested in the $Y$ maze, which consists of three white, opaque plastic arms at a $120^{\circ}$ angle from each other. The ability to alternate requires that the mice know which arms have already been visited. Therefore, alternation behavior can be regarded as a measure of spatial working memory [14]. During the test session, each mouse was placed at the end of one arm and allowed to move freely through the maze during a 10-minute session. The total number of arm entries (locomotor activity) and alternations (defined as consecutive entries into all three arms without repetitions, in overlapping triplet sets) were scored.

2.2.3. Elevated plus maze-TL was tested using an elevated plus maze consisting of two open arms $(30 \times 5 \times 2.5 \mathrm{~cm})$ and two enclosed arms $(30 \times 5 \times 15 \mathrm{~cm})$. The maze was elevated to the height of $50 \mathrm{~cm}$. Mice were placed individually at the end of an open arm facing away from the central platform, and the time it took to move from the end of the open arm to either of the closed arms (TL) was recorded. The TL was expressed as retention after 24hours by calculating the inflexion ratio (IR) using the formula

$$
(\mathrm{IR})=\frac{\mathrm{L} 1-\mathrm{L} 0}{\mathrm{~L} 0},
$$

where IR is the inflexion ratio, $\mathrm{L} 0$ is the TL after 24 hours, and L1 is the initial TL in seconds.

\subsection{Western blotting}

Cerebral cortical tissues were homogenized in RIPA buffer containing a protease inhibitor cocktail (Sigma-Aldrich), incubated on ice for 1 hour, then centrifuged at $3500 \mathrm{~g}$ for 20 minutes [3]. The supernatant was collected and used for Western blot analysis. Protein concentration was determined by using a BCA kit (Pierce Biotechnology Inc.Rockford, IL, USA). For amyloid beta precursor protein (A $\beta \mathrm{PP})$ and specificity protein 1 (Sp1) proteins, $40 \mu \mathrm{g}$ protein was separated via $10 \%$ sodium dodecyl sulfate-polyacrylamide gel electrophoresis. Nonspecific binding was blocked by incubation with $5 \%$ bovine serum albumin (BSA) in Tris buffer Saline + 0.1\% Tween 20 (TBST) at room temperature for 1 hour. Immunoblotting was performed after overnight exposure to the following antibodies diluted at 1:1000 with gentle agitation on a shaker at $4^{\circ} \mathrm{C}$ : $\mathrm{A} \beta \mathrm{PP}$ (anti-Alzheimer precursor protein $\mathrm{A} 4$, amino acids $66-81$ of $\mathrm{A} \beta \mathrm{PP}$ [N-terminus], clone $22 \mathrm{C} 11$ mouse monoclonal) and anti-Sp1 rabbit polyclonal (Millipore, Billerica, MA, USA). On the following day, membranes were washed and exposed for 1 hour to IRDye 680LT Infrared Dye (LI-COR Biotechnology, Lincoln, NE, USA), goat antimouse/goat antirabbit diluted at 1:10,000. The images were developed using an Odyssey infrared imaging system (model 9120; LI-COR Biotechnology, Lincoln, NE, USA). As a control for equal protein loading, membranes were stripped and reprobed with rabbit $\beta$-actin antibody (diluted at 1:2500; Sigma-Aldrich, St. Louis, MO, USA) and exposed to antirabbit IRDye 680LT Infrared Dye. After transferring to a polyvinylidene difluoride membrane, the gel was stained with Bio-safe Coomassie blue stain (Bio-Rad, Hercules, CA, USA) to assess the loading of the samples. 


\subsection{Total RNA isolation, synthesis of complementary DNA, and real-time polymerase chain reaction}

RNA from the brain tissue was isolated according to the TRIzol method (Invitrogen). Firststrand complementary DNA (cDNA) was synthesized from $1.5 \mu \mathrm{g}$ total RNA using the iScript cDNA synthesis kit (Bio-Rad, Hercules, CA, USA). cDNA was then amplified using real-time polymerase chain reaction. The SYBR Green quantitative real-time polymerase chain reaction assay was performed in $25-\mu \mathrm{L}$ reactions in triplicate using $1.5 \mu \mathrm{L}$ cDNA template, $1 \times \mathrm{SYBR}$ Green master mix, $0.4 \mu \mathrm{M}$ forward and reverses primers, and deionized $\mathrm{H}_{2} \mathrm{O}$. The following primers were used: A $\beta$ PP forward primer, 5'-GGT TCT GGG CTG ACA AAC AT-3'; A $\beta$ PP reverse primer, 5'-GTG ATG ACA ATC ACG GTT GC-3'; Sp1 forward primer, 5'-TCA TAC CAG GTG CAA ACC AA-3'; Sp1 reverse primer, 5'-AGG TGA TGT TCC CAT TCA GG-3'; $\beta$-site amyloid precursor protein (APP) cleaving enzyme 1 (BACE1) forward primer, 5' ATG TGC ACG ATG AGT TCA GG-3'; and BACE1 reverse primer, 5'-GCA GAG TGG CAA CAT GAA GA-3'. Amplification was undertaken on an ABI PRISM 7500 machine (Applied Biosystems, Foster City, CA, USA) with sequence detection software version 1.3, and expression was reported relative to glyceraldehyde-3-phosphate dehydrogenase mRNA with the $2^{-\Delta \Delta \mathrm{Ct}}$ method.

\subsection{Enzyme-linked immunosorbent assay $A \beta(1-40)$ and $A \beta$ (1-42)}

The levels of $A \beta$ were measured using human $A \beta(1-40)$ and (1-42) assay kits. These kits are solid-phase sandwich enzyme-linked immunosorbent assays with two kinds of highly specific antibodies, which are $100 \%$ reactive with mouse $A \beta 1-40$ and $70 \%$ reactive with mouse A $\beta 1-42$. The assay was conducted according to the manufacturer's instructions (Immuno-Biological Laboratories, Gunma, Japan) with minor modifications [15]. One hundred micrograms of protein samples in $100 \mu \mathrm{L}$ EIA buffer and assay standards were added to 96-well plates precoated with anti-human $A \beta$ mouse immunoglobulin $G$ monoclonal antibody. The plates were incubated overnight at $4^{\circ} \mathrm{C}$, and were washed seven times using the $40 \times$ diluted wash buffer supplied with the kit $(0.05 \%$ Tween 20 in phosphate buffer). Afterward, $100 \mu \mathrm{L}$ labeled antibody were added to the samples and standards, followed by incubation at $4^{\circ} \mathrm{C}$ for 1 hour. After incubation, the plates were washed nine times followed by the addition of $100 \mu \mathrm{L}$ tetramethylbenzidine as a coloring agent. The plates were incubated in the dark for 30 minutes at room temperature. Last, $100 \mu \mathrm{L} 1 \mathrm{~N}$ $\mathrm{H}_{2} \mathrm{SO}_{4}$ was added to stop the reaction, and absorbance was measured at $450 \mathrm{~nm}$ using a Spectra Max UV/Vis Spectrometer (GMI, Inc.). The levels of A $\beta$ in the test samples were calculated relative to the standard curve generated for each plate.

\subsection{BACE1 activity assay}

$\beta$-Secretase activity was measured with a BACE1 activity kit (SensiZyme BACE1 Activity Assay Kit, Sigma-Aldrich, Saint Louis, MO, USA) according to the manufacturer's protocol. The enzymatic reactionfor secretase activity was carried out in an anti-BACE1coated 96-well plate. The $100 \mu \mathrm{L}$ of standards and test samples were pipetted into each well and incubated for 2 hour at $2^{\circ} \mathrm{C}$ to $8^{\circ} \mathrm{C}$. The solution was aspirated from the wells and washed four times with wash buffer. A $50-\mu \mathrm{L}$ substrate (proenzyme) was added to each well and was incubated overnight at room temperature in a humidified chamber. On the following day, $50 \mu \mathrm{L}$ reagent mixture (substrate B + dithiothreitol (DTT) was added to each well followed by shaking for 20 seconds. The plate was incubated again at room temperature for a couple hours and then absorbance was measured at $405 \mathrm{~nm}$ using a plate reader. The activity of BACE1 is presented in nanograms per milliliter. 


\subsection{Statistical analysis}

Western blot bands were quantified by using the LI-COR/Odyssey infrared image system. All measurements were made in triplicate and all values are presented as mean \pm standard error of the mean. The significance of the difference among means of the experimental groups was obtained with one-way analysis of variance, the Tukey-Kramer multiplecomparison posttest, and the student Newman-Keuls comparison posttest, using Graph pad Prism 3.0 computer software(La Jolla, CA, USA). The level of significance was set at $P<$. 05.

\section{Results}

\subsection{Effect of developmental $\mathrm{Pb}$ exposure on performance in the Morris water maze}

The $\mathrm{Pb}$ exposure model that we have used in several life span studies does not result in nutritional disturbances, as evidenced by the absence of changes in weight or any overt changes in brain structure or anatomy. The death rate of the aging animals was not any different from that in controls $[3,6]$. The Pb levels in the two age groups, PND 20 and PND 700 , have been monitored and published in previous studies [16]. We found that at 20 days after exposure, the $\mathrm{Pb}$ blood level was $46.13 \pm 1.95 \mu \mathrm{g} / \mathrm{dL}$ and the brain level were $0.41 \pm$ $0.04 \mu \mathrm{g} / \mathrm{g}$ wet weight. $\mathrm{Pb}$ levels in the aging animals are at background levels in both the control and animals with prior exposure to $\mathrm{Pb}$.

Exposure of mice to the developmental neurotoxicant $\mathrm{Pb}$ under different scenarios was tested in the spatial learning tasks of the Morris water maze at PND 540 and PND 700. Learning, assessed by the reduction in latency to find the hidden platform during 7 days of training, was clearly evident for the control and PbA groups, and was no different at PND 540 and PND 700 for these groups. However, our results indicate that mice from the PbE (developmental exposure only) and PbEA (developmental and adult exposure) groups, which were tested at PND 540, exhibited a significant $(P<.05)$ increase in latency at day 7 of training (Fig. 1A). Likewise, mice from the PbE and PbEA groups, which were tested at PND 700, showed a significant delay $(P<.05, P<.01)$ in latency from day 2 , which was consistent until day 6 of training compared with age-matched controls; these mice never found the platform within 20 seconds during the acquisition phase (Fig. 2A). The deficit in memory was also confirmed in the $\mathrm{PbE}$ and $\mathrm{PbEA}$ groups by probe tria ls undertaken on day 8. A significant decrease $(P<.05, P<.01)$ in the percentage time spent and distance traveled in the target quadrant was observed in these mice at PND 540 (Fig. 1B, C), and memory deficiency was observed to be most significant $(P<.001)$ at PND 700 compared with agedmatched controls (Fig. 2B, C).

\subsection{Effect of early life $\mathrm{Pb}$ exposure on $\mathrm{Y}$ maze performance and $\mathrm{TL}$}

Analysis of the results from the Y maze task of the four groups at time points PND 540 and PND 700 reveal a significant $(P<.05, P<.01)$ reduction in the spontaneous alternation in the $\mathrm{PbE}$ and $\mathrm{PbEA}$ groups at both time points of analysis (Fig. 3A, B). Similarly, TL of first day reflected learning behavior of animals, whereas TL of second day reflected retention of information, or memory. Our results revealed a significant $(P<.05, P<.01)$ decrease in the inflexion ratio of the PbE and PbEA groups at time points PND 540 and PND 700 compared with the control group (Fig. 3C, D).

\subsection{Latent protein expression of A $\beta$ PP and Sp1}

The protein expressions of $\mathrm{A} \beta \mathrm{PP}$ and Sp1 relative to $\beta$-actin were profiled by Western blotting at different time points during the life span of the experimental mice. Normalized $\mathrm{A} \beta \mathrm{PP}$ levels in the $\mathrm{PbE}$ and $\mathrm{PbEA}$ groups compared with the control group were found to 
slightly increase during development, remained steady during adulthood, and increased significantly $(P<.05)$ in old age (Fig. 4A, B). Similarly, normalized Sp1 levels in the $\mathrm{PbE}$ and $\mathrm{PbEA}$ groups displayed an increase on PND 20, which showed a significant $(P<.05)$ increase in old age (Fig 5A, B). No significant change in the protein expression of $\mathrm{A} \beta \mathrm{PP}$ and $\mathrm{SP} 1$ was observed in the PbA group.

\subsection{Effect of aging and developmental exposure of $\mathrm{Pb}$ on $\mathrm{A} \beta$ levels and BACE1 activity}

Changes in A $\beta 1-40$ and $A \beta 1-42$ levels were examined by enzyme-linked immunosorbent assay at PNDs 20, 180, 270, 540, and 700. Our results revealed that the PbA group displayed no change in $A \beta$ levels at various time points of analysis. On the other hand, an increase in the levels of $A \beta 1-40$ and $A \beta 1-42$ was observed in the PbE and PbEA groups at PND 270, which was significantly pronounced $(P<.05)$ on PND 700 (Fig. 6A, B). The ratio of A $\beta 1-42$ to A $\beta 1-40$ on PND 20 and PND 700 for the PbE and PbEA groups displayed a significant $(P<.05)$ increase at PND 20 compared with age-matched groups, with a greater change in the ratio at PND $700(P<.001)$. The PbA group did not show any significant change in the ratio at PND 20 or PND 700 (Fig. 6C). Our results further demonstrate a significant ( $r=$ $-0.42, P<.03)$ correlation between $\mathrm{A} \beta 1-40$ levels and the percentage of time spent in the correct quadrant during the probe trial in the water maze task for 700-day-old mice. A correlation between $\mathrm{A} \beta 1-42$ and percentage of time spent in the correct quadrant during the probe trial in the water maze by same age group showed a similar trend $(r=-0.389, P<.06)$.

BACE1 is the proteolytic enzyme that generates the N-terminus of the $A \beta$ peptide. Our study shows that BACE1 activity in the control and $\mathrm{PbA}$ groups remained relatively steady in young and aging mice. Developmental exposure of mice to $\mathrm{Pb}$ was found to induce a significant $(P<.05)$ increase in the BACE1 activity in the PbEA group at PND 500. A significant increase was also evident in the $\mathrm{PbE}$ and PbEA groups at PND 700 compared with age-matched controls (Fig. 6D).

\subsection{Effect of aging and $\mathrm{Pb}$ exposure on AßPP, BACE1, and Sp1 mRNA expression}

In the five age groups studied, normalized A $\beta \mathrm{PP}, \mathrm{BACE} 1$, and Sp1 mRNA expression was evaluated for control as well as mice with stage-specific exposure to $\mathrm{Pb}$. Our results indicate that the $\mathrm{PbE}$ and $\mathrm{PbEA}$ groups showed a significant $(P<.05)$ latent upregulation of mRNA expression of A $\beta \mathrm{PP}$ (Fig. 4C), Sp1 (Fig. 5C), and BACE1 (Fig. 6E) at PND 700 compared with aged-matched controls. No significant change in mRNA expression was observed in the $\mathrm{PbA}$ group compared with the control group.

\section{Discussion}

Heavy metals such as $\mathrm{Pb}$ pose a widespread environmental concern, and persistent human exposure to low levels of $\mathrm{Pb}$ has been a matter of public concern worldwide [17]. Exposure to $\mathrm{Pb}$ is the most prevalent, and $\mathrm{Pb}$ is the most insidious environmental toxin affecting children, particularly during the perinatal stage. Children have been found to be cognitively impaired at blood levels below the Centers for Disease Control and Prevention safe level of $10 \mu \mathrm{g} / \mathrm{dL}[18,19]$. Although, exposure to $\mathrm{Pb}$ is widely recognized to be a risk factor for the health of children and adults, our studies are the first to reveal that early life exposure has a latent effect on neurodegenerative diseases $[4,6]$, thereby providing the first environmental model of early life exposure that predetermines outcomes of the aging brain through epigenetic reprogramming [6].

Previous studies by us focused on molecular and biochemical changes in old age resulting from infantile exposure to $\mathrm{Pb}$. In the current study, we conducted comprehensive behavioral testing on aging animals exposed exclusively to $\mathrm{Pb}$ during the early developmental stage 
and/or reexposed again as adults. The performance of these animals was compared with siblings with no exposure (controls) or siblings exposed as adults only ( $\mathrm{PbA}$ ). Animals with a developmental component of exposure were impaired in their performance at 18 months of age, which was much pronounced at 24 months (Figs. 1 and 2), whereas animals exposed as adults only performed similar to controls. In the $\mathrm{Y}$ maze test as well, animal groups with a developmental component of exposure showed a decrease in spontaneous alternations at PND 540 and PND 700 compared with age-matched controls (Fig. 3A, B). These findings demonstrate that the perinatal developmental stage is a critical period of exposure and has an effect on cognitive function later in life.

Past reports from our laboratory have demonstrated that $A \beta P P$ mRNA and protein expression in the cerebral cortex increase with age and are abnormally elevated in older rats or primates exposed to $\mathrm{Pb}$ as infants [3,4]. Similar results were also observed in an in vitro study in which differentiated SH-SY5Y cells were exposed to $\mathrm{Pb}$ early and were allowed to live for about a month [20]. Consistent with the earlier studies, control animals, which represent normal aging, displayed an increase in APP expression in late life; however, mice exposed to $\mathrm{Pb}$ during developmental phases showed a drastic increase in the protein and mRNA levels of APP. This latent increase in APP was also accompanied by commensurate elevation in $A \beta$ levels. The ratio of $A \beta 1-42$ to $A \beta 1-40$ in rodents with developmental exposure to $\mathrm{Pb}$ was also found to be significantly elevated late in life $[3,4]$.

Furthermore, consistent with our earlier findings, a significant increase in BACE1 activity and mRNA levels was observed in mice exposed to $\mathrm{Pb}$ as pups [21]. Sp1 was also similarly increased late in life (Fig. 5), commensurate with the role of $\mathrm{Sp} 1$ as an essential regulator of the A $\beta P P$ gene $[3,22,23]$, and is in agreement with previous findings[21,24]. What is striking is that the changes in the AD-related genes and their products mirror the behavioral outcomes, supporting the hypothesis that there is a developmental window of vulnerability to low levels of $\mathrm{Pb}$ exposure.

Although no direct evidence is presented vis-à-vis the latent cognitive deficits and latent alterations in the amyloid pathway, supporting evidence for the relationship between the amyloidogenic pathway and the decline in cognitive capacities late in life are as follows: (1) both the cognitive decline and the alterations in amyloid intermediates occur late in life, (2) the life span profiles of the amyloid intermediates are not altered in animals unexposed during development nor is there any cognitive decline in animals exposed as adults only, and (3) correlational analysis of some behavioral tasks suggests a possible relationship. Thus, these findings suggest that cognitive deficits occurring in old age are related to alterations in the status of the amyloid pathway as a result to developmental $\mathrm{Pb}$ exposure.

To explain these latent changes in gene expression, the proposed mechanisms must include long-term epigenetic modification in the structural architecture of the DNA bases that regulate the accessibility of transcription factors to these genes. Past reports have revealed that Sp1, BACE, and APP genes are rich in cytosine-phosphate-guanine (CpG) dinucleotide and guanine-cytosine (GC) box elements [25], thus making them targets for epigenetic modification via DNA methylation. These characteristic features of the A $\beta P P$ gene and the other AD-related genes such as BACE, previously shown by us to be altered late in life as a result of early-life $\mathrm{Pb}$ exposure, suggest that the genes with promoters that are rich in $\mathrm{CpG}$ dinucleotides can be the prime candidates for epigenetic reprogramming. The reduced activity and protein levels of DNA methylating enzymes DNMT1 and DNMT3 A, which we observed in aging animals as well as in cultured cells that had prior exposure to $\mathrm{Pb}[21,26]$, is consistent with the upregulation of some genes observed in old age. Furthermore, recent discoveries that DNMT3 A levels are directly related to cognitive decline in old age lends more support to this hypothesis, especially because this enzyme is also regulated 
developmentally [27]. However, both upregulation and downregulation of genes occur in older animals exposed to $\mathrm{Pb}$ as infants and, in either case, DNA methylation appears to play an important role [6]. Hence, early-life exposure to $\mathrm{Pb}$ interferes with DNA methylation patterns of genes, which is then sustained throughout life and has an impact during old age.

In conclusion, our results indicate that early exposure to the environmental toxicant $\mathrm{Pb}$ causes a significant cognitive deficit late in life that is accompanied by latent upregulation in $\mathrm{AD}$ biomarkers $\mathrm{A} \beta \mathrm{PP}, \mathrm{A} \beta$, and $\mathrm{BACE} 1$. This study demonstrates that development is an important period that is vulnerable to environmental toxicants, which could increase future disease susceptibility, including $\mathrm{AD}$, potentially through epigenetic reprogramming.

\section{Acknowledgments}

This research was supported by the Intramural Research Program of the National Institutes of Health (NIH), National Institute of Environmental Health Sciences, and by grant NIH-5RO1ES015867-03. The research core facility was funded (P20RR016457) by the National Center for Research Resources, a component of NIH.

\section{References}

[1]. Selkoe DJ. Amyloid protein and Alzheimer's disease. Sci Am. 1991; 265:68-71. 74-6, 78. [PubMed: 1785042]

[2]. Tanzi RE, Bertram L. Alzheimer's disease: the latest suspect. Nature. 2008; 454:706-8. [PubMed: 18685694]

[3]. Basha MR, Wei W, Bakheet SA, Benitez N, Siddiqi HK, Ge YW, et al. The fetal basis of amyloidogenesis: exposure to lead and latent overexpression of amyloid precursor protein and beta-amyloid in the aging brain. J Neurosci. 2005; 25:823-9. [PubMed: 15673661]

[4]. Wu J, Basha MR, Brock B, Cox DP, Cardozo-Pelaez F, McPherson CA, et al. Alzheimer's disease (AD)-like pathology in aged monkeys after infantile exposure to environmental metal lead $(\mathrm{Pb})$ : evidence for a developmental origin and environmental link for AD. J Neurosci. 2008; 28:3-9. [PubMed: 18171917]

[5]. Alashwal H, Dosunmu R, Zawia NH. Integration of genome-wide expression and methylation data: relevance to aging and Alzheimer's disease. Neurotoxicology. 2012; 33:1450-3. [PubMed: 22743688]

[6]. Dosunmu R, Alashwal H, Zawia NH. Genome-wide expression and methylation profiling in the aged rodent brain due to early-life $\mathrm{Pb}$ exposure and its relevance to aging. Mech Ageing Dev. 2012; 133:435-43. [PubMed: 22613225]

[7]. Payton M, Riggs KM, Spiro A 3rd, Weiss ST, Hu H. Relations of bone and blood lead to cognitive function: the VA Normative Aging Study. Neurotoxicol Teratol. 1998; 20:19-27. [PubMed: 9511166]

[8]. Weisskopf MG, Wright RO, Schwartz J, Spiro A 3rd, Sparrow D, Aro A, et al. Cumulative lead exposure and prospective change in cognition among elderly men: the VA Normative Aging Study. Am J Epidemiol. 2004; 160:1184-93. [PubMed: 15583371]

[9]. Weisskopf MG, Proctor SP, Wright RO, Schwartz J, Spiro A 3rd, Sparrow D, et al. Cumulative lead exposure and cognitive performance among elderly men. Epidemiology. 2007; 18:59-66. [PubMed: 17130688]

[10]. Wright RO, Tsaih SW, Schwartz J, Spiro A 3rd, McDonald K, Weiss ST, et al. Lead exposure biomarkers and Mini-Mental Status Exam scores in older men. Epidemiology. 2003; 14:713-8. [PubMed: 14569188]

[11]. Weuve J, Korrick SA, Weisskopf MG, Ryan LM, Schwartz J, Nie H, et al. Cumulative exposure to lead in relation to cognitive function in older women. Environ Health Perspect. 2009; 117:574-80. [PubMed: 19440496]

[12]. Dosunmu R, Wu J, Adwan L, Maloney B, Basha MR, McPherson CA, et al. Life span profiles of Alzheimer's disease-associated genes and products in monkeys and mice. J Alzheimers Dis. 2009; 18:211-30. [PubMed: 19584442] 
[13]. Morris RG, Garrud P, Rawlins JN, O'Keefe J. Place navigation impaired in rats with hippocampal lesions. Nature. 1982; 297:681-3. [PubMed: 7088155]

[14]. Sarter M, Bodewitz G, Stephens DN. Attenuation of scopolamine-induced impairment of spontaneous alteration behaviour by antagonist but not inverse agonist and agonist betacarbolines. Psychopharmacology (Berl). 1988; 94:491-5. [PubMed: 2836875]

[15]. Morishima-Kawashima M, Oshima N, Ogata H, Yamaguchi H, Yoshimura M, Sugihara S, et al. Effect of apolipoprotein E allele epsilon4 on the initial phase of amyloid beta-protein accumulation in the human brain. Am J Pathol. 2000; 157:2093-9. [PubMed: 11106581]

[16]. Basha MR, Murali M, Siddiqi HK, Ghosal K, Siddiqi OK, Lashuel HA, et al. Lead (Pb) exposure and its effect on APP proteolysis and Abeta aggregation. FASEB J. 2005; 19:2083-4. [PubMed: 16230335]

[17]. Tong S, von Schirnding YE, Prapamontol T. Environmental lead exposure: a public health problem of global dimensions. Bull World Health Organ. 2000; 78:1068-77. [PubMed: 11019456]

[18]. Patrick L. Lead toxicity, a review of the literature. Part 1: exposure, evaluation, and treatment. Altern Med Rev. 2006; 11:2-22. [PubMed: 16597190]

[19]. Canfield RL, Henderson CR Jr, Cory-Slechta DA, Cox C, Jusko TA, Lanphear BP. Intellectual impairment in children with blood lead concentrations below $10 \mu \mathrm{g}$ per deciliter. N Engl J Med. 2003; 348:1517-26. [PubMed: 12700371]

[20]. Huang H, Bihaqi SW, Cui L, Zawia NH. In vitro Pb exposure disturbs the balance between Abeta production and elimination: the role of AbetaPP and neprilysin. Neurotoxicology. 2011;32:3006. [PubMed: 21315759]

[21]. Bihaqi SW, Zawia NH. Alzheimer's disease biomarkers and epigenetic intermediates following exposure to Pb in vitro. Curr Alzheimer Res. 2012; 9:555-62. [PubMed: 22272629]

[22]. Docagne F, Gabriel C, Lebeurrier N, Lesne S, Hommet Y, Plawinski L, et al. Sp1 and Smad transcription factors co-operate to mediate TGF-beta-dependent activation of amyloid-beta precursor protein gene transcription. Biochem J. 2004; 383:393-9. [PubMed: 15242331]

[23]. Lukiw WJ, Rogaev EI, Wong L, Vaula G, McLachlan DR, St. George Hyslop P. Protein-DNA interactions in the promoter region of the amyloid precursor protein (APP) gene in human neocortex. Brain Res Mol Brain Res. 1994; 22:121-31. [PubMed: 8015372]

[24]. Brock B, Basha R, DiPalma K, Anderson A, Harry GJ, Rice DC, et al. Co-localization and distribution of cerebral APP and SP1 and its relationship to amyloidogenesis. J Alzheimers Dis. 2008; 13:71-80. [PubMed: 18334759]

[25]. Pollwein P, Masters CL, Beyreuther K. The expression of the amyloid precursor protein (APP) is regulated by two GC-elements in the promoter. Nucl Acids Res. 1992; 20:63-8. [PubMed: 1738605]

[26]. Bihaqi SW, Huang H, Wu J, Zawia NH. Infant exposure to lead (Pb) and epigenetic modifications in the aging primate brain: implications for Alzheimer's disease. J Alzheimers Dis. 2011; 27:819-33. [PubMed: 21891863]

[27]. Oliveira AM, Hemstedt TJ, Bading H. Rescue of aging-associated decline in DNMT3a2 expression restores cognitive abilities. Nat Neurosci. 2012; 15:1111-3. [PubMed: 22751036] 


\section{RESEARCH IN CONTEXT}

1. Systematic review: We have conducted a literature review and together with our previous reports we established a link between early life exposure and amyloidogenesis. While previous studies focused on molecular and biochemical changes, we sought to investigate the functional impact of early life exposure on behavioral outcomes on aging animals. In addition, we examined the changes on amyloidogenic proteins following early and adult exposure to lead at multiple time points during the life span of mice.

2. Interpretation: These findings affect the early origins of $\mathrm{AD}$ and support environmental metal lead as a risk factor for $\mathrm{AD}$ and cognitive decline in old age. The data provides further evidence that the developmental stage is vulnerable to environmental toxicants leading to increase in disease susceptibility in adulthood.

3. Future directions: the current study provides evidence of a relation between early life exposure to lead and cognitive changes at old age. While we have examined the changes in the amyloidogenic pathway, it is important to further study lead's effects on the other hallmark of AD, tau pathology. In addition, it is crucial to investigate the possible mechanisms leading to those changes, including epigenetic reprogramming. 

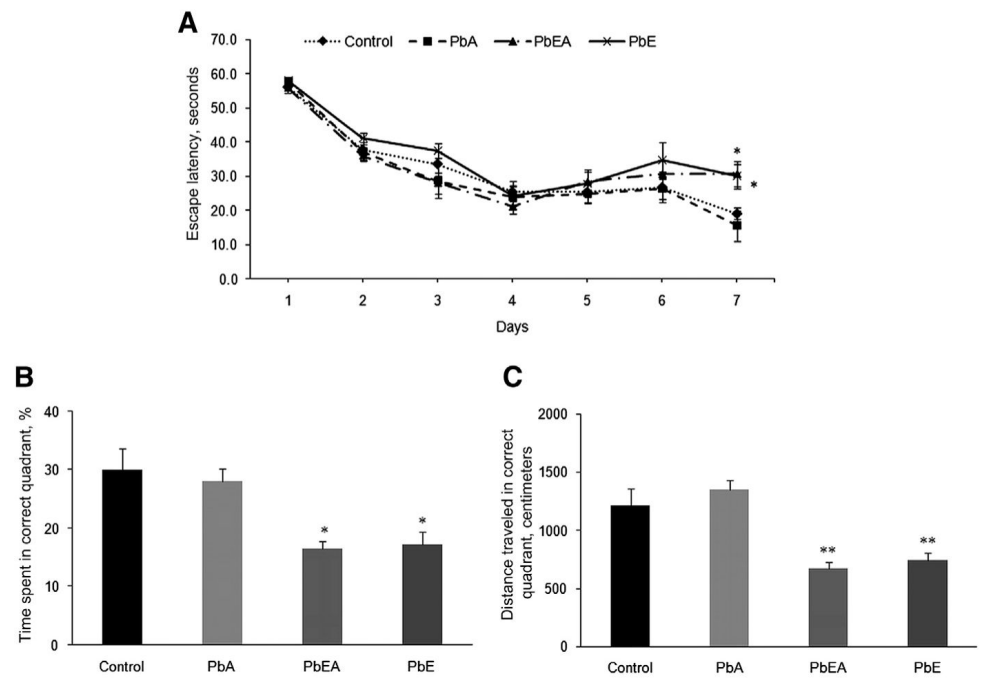

Fig. 1.

Acquisition and memory retention in 18-month old mice. Training in the Morris water maze consisted of three trials per day for 7 days to locate a hidden platform. Memory retention was assessed by a 60-secoond probe trial 24 hours after the last day of acquisition testing. (A) Mean escape latencies for finding the platform during daily training sessions. (B) Probe trial data representing the time spent in the target quadrant where the platform was located during training. (C) Probe trial data representing the distance traveled in the correct quadrant. Values are expressed as mean \pm standard error of the mean. $* P<.05$ compared with control. $* * P<.01$ compared with control. $\mathrm{PbA}$, adult lead exposure group; $\mathrm{PbE}$, early lead exposure group; PbEA, early and adult lead exposure group. 


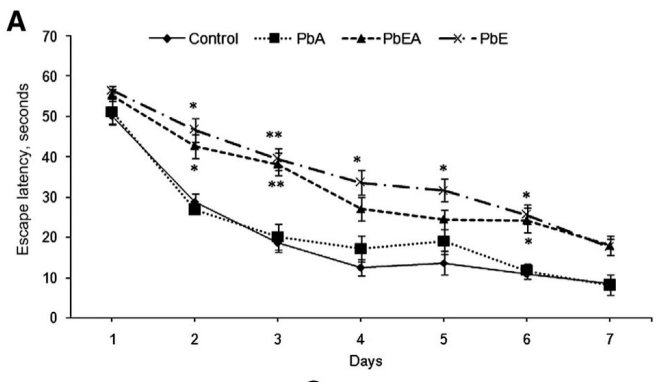

B

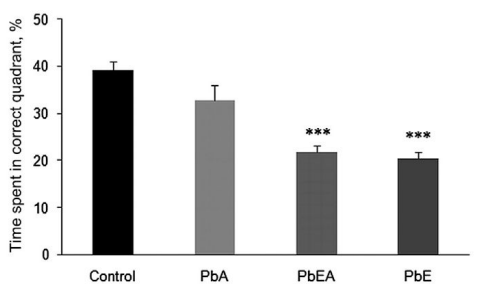

C

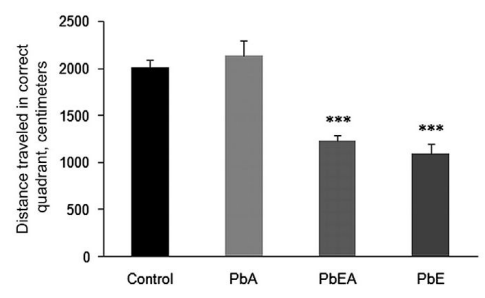

Fig. 2.

Acquisition and memory retention in 24-month-old mice. Training in the Morris water maze consisted of three trials per day for 7 days to locate a hidden platform. Memory retention was assessed by a 60 -second probe trial 24 hours after the last day of acquisition testing. (A) Mean escape latencies for finding the platform during daily training sessions. (B) Probe trial data representing the time spent in the target quadrant, where the platform was located during training. (C) Probe trial data representing the distance traveled in the correct quadrant. Values are expressed as mean \pm standard error of the mean. $* P<.05$ compared with control. $* * P<.01$ compared with control. $* * * P<.001$ compared with control. $\mathrm{PbA}$, adult lead exposure group; $\mathrm{PbE}$, early lead exposure group; PbEA, early and adult lead exposure group. 

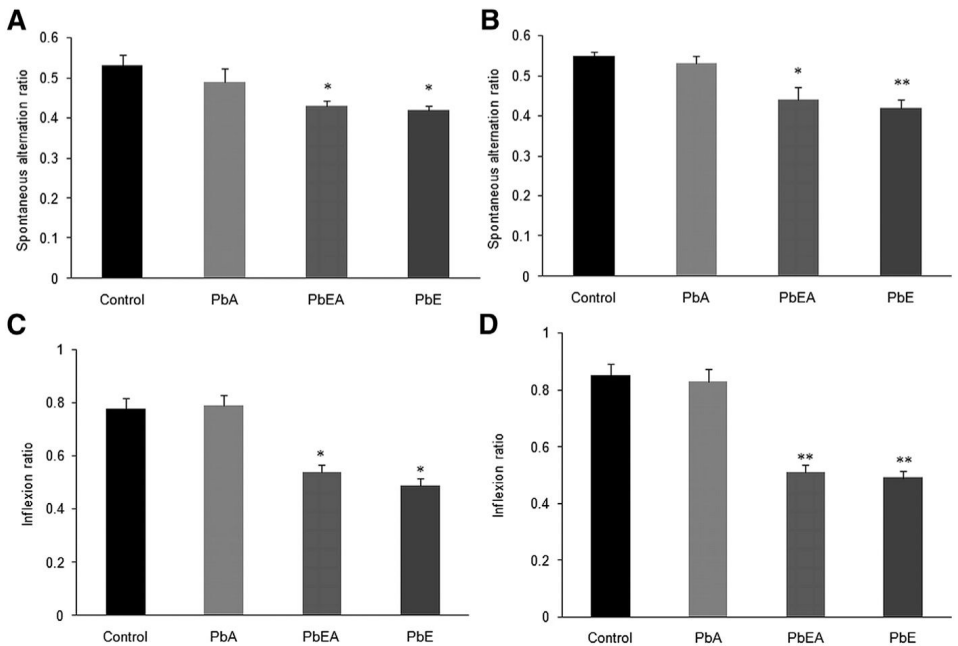

Fig. 3.

Developmental exposure to $\mathrm{Pb}$ affects spontaneous alternations and transfer latency in older mice. (A, B) Mice were tested for spatial working memory as measured by assessing the spontaneous alternations in $\mathrm{Y}$ maze at 18 months of age (A) and at 24 months of age (B). (C, D) Retention memory using the transfer latency as a parameter for acquisition and retention memory expressed as the inflexion ratio were also assessed in the elevated plus maze at 18 months of age (C) and 24 months of age (D). Data was expressed as mean \pm standard error of the mean. ${ }^{*} P<.05$ compared with control. $* * P<.01$ compared with control. PbA, adult lead exposure group; $\mathrm{PbE}$, early lead exposure group; $\mathrm{PbEA}$, early and adult lead exposure group. 
A

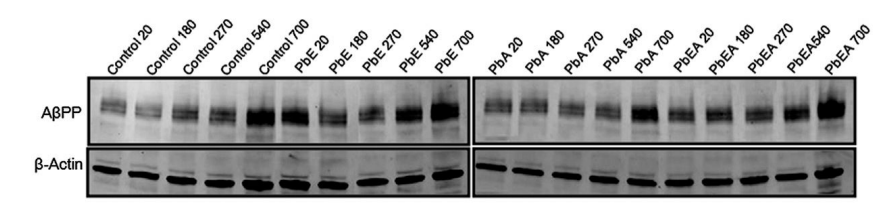

B

C
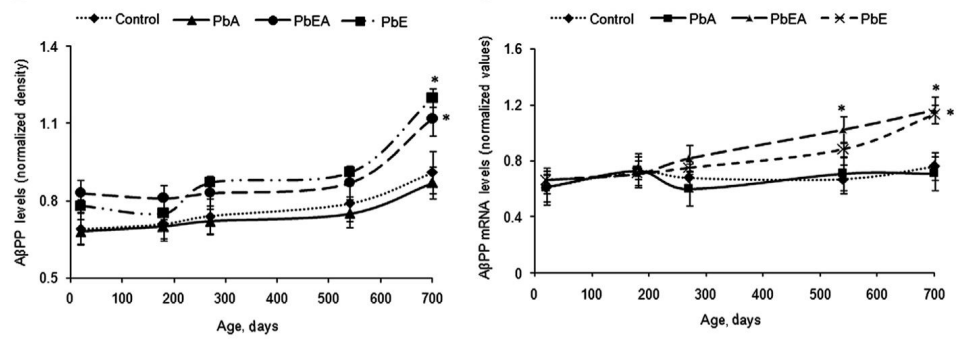

Fig. 4.

Amyloid- $\beta$ precursor protein (A $\beta \mathrm{PP}$ ) expression across the life span and after developmental exposure to lead $(\mathrm{Pb})$. (A) Changes in life span profiles of $A \beta P P$ protein expression in the cerebral cortex of control (Control), early $\mathrm{Pb}$ exposure group $(\mathrm{PbE})$, adult $\mathrm{Pb}$ exposure group $(\mathrm{PbA})$, and early and adult $\mathrm{Pb}$ exposure group $(\mathrm{PbEA})$ measured by Western blot analysis as described in Methods. (B) Quantification of A $\beta$ PP Western blot bands normalized to $\beta$-actin levels. (C) Life span messenger RNA (mRNA) levels of A $\beta$ PP relative to glyceraldehyde-3phosphate dehydrogenase. Each data point in the curve is the mean \pm standard error of the mean. ${ }^{*} P<.05$ compared with control. 

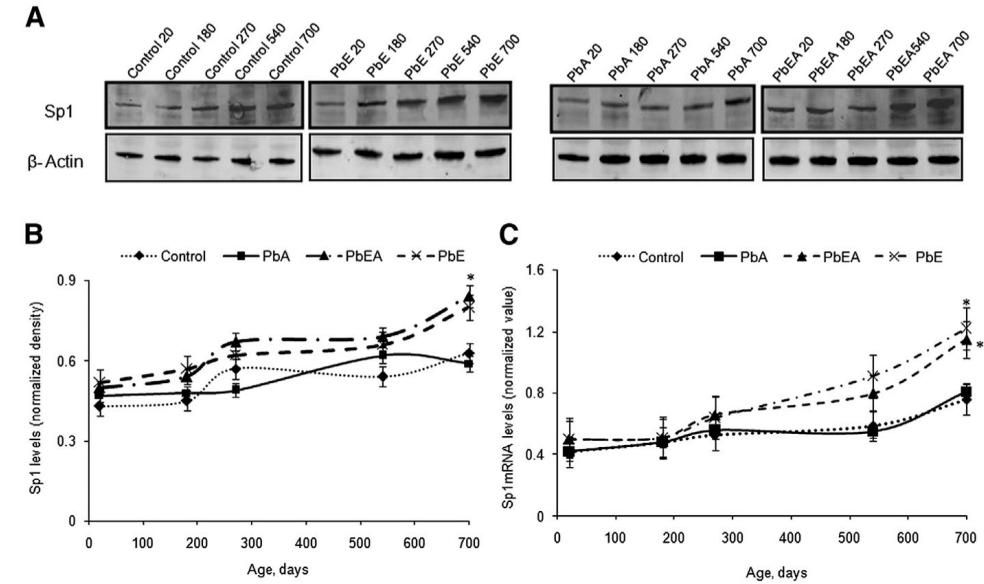

Fig. 5.

Specificity protein $1(\mathrm{Sp} 1)$ life span expression profiles and levels in mice cortex with infantile exposure to lead $(\mathrm{Pb})$. (A) Changes in the life span profiles of $\mathrm{Sp} 1$ were measured in the cerebral cortex of the control (Control), early $\mathrm{Pb}$ exposure group ( $\mathrm{PbE})$, adult $\mathrm{Pb}$ exposure group $(\mathrm{PbA})$, and early and adult $\mathrm{Pb}$ exposure group $(\mathrm{PbEA})$ using Western blot analysis as described in Methods. (B) Quantification of SP1 Western blot bands after normalization to $\beta$-actin levels. (C) Life span messenger RNA (mRNA) levels of Sp1 relative to glyceraldehyde-3-phosphate dehydrogenase. Each data point in the curve is the mean \pm standard error of the mean SEM. $* P<.05$ compared with control. 

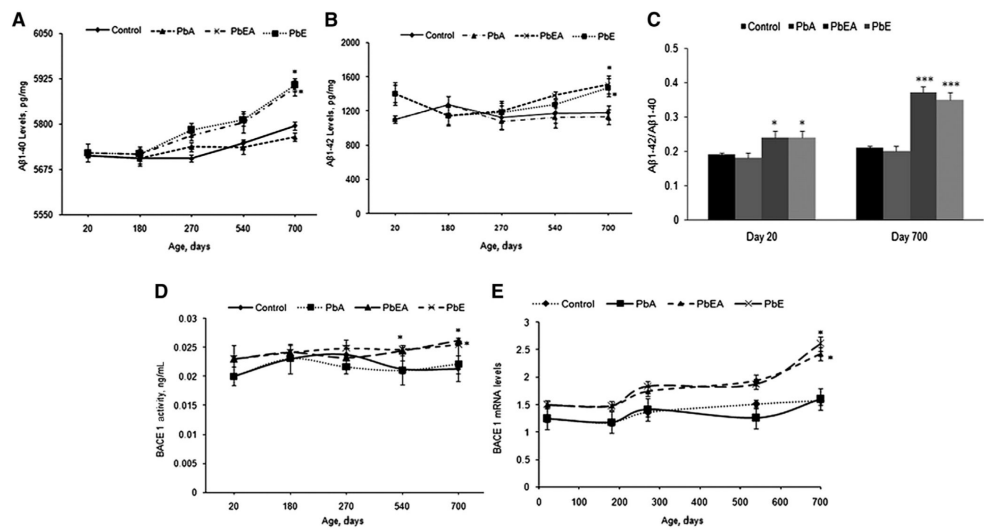

E

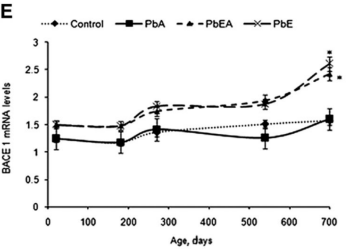

Fig. 6.

$\beta$-Site amyloid precursor protein cleaving enzyme 1 (BACE1) activity, BACE1 messenger RNA (mRNA) levels, and amyloid beta (A $\beta$ ) life span expression profiles in mice cortex with infantile exposure to lead $(\mathrm{Pb})$. (A, B) Changes in the life span profiles of $\mathrm{A} \beta 1-40(\mathrm{~A})$ and $A \beta 1-42$ (B). (C) The ratio of $A \beta 1-42$ to A $\beta 1-40$ in postnatal day (PND) 20 and PND 700 mice using enzyme-linked immunosorbent assay as described in Methods. (D) Changes in BACE1 activity were measured in the cerebral cortex of the control (Control), early $\mathrm{Pb}$ exposure group $(\mathrm{PbE})$, adult $\mathrm{Pb}$ exposure group $(\mathrm{PbA})$, and early and adult $\mathrm{Pb}$ exposure group (PbEA). (E) Life span mRNA levels of BACE1 relative to glyceraldehyde-3phosphate dehydrogenase. Values are expressed as mean \pm standard error of the mean. $* P<$. 05 compared with the control group. ${ }^{* * *} P<.001$ compared with the control group. 